\title{
Stereoselective Aldol Reaction in Aqueous Solution Using Prolinamido-Glycosides as Water-Compatible Organocatalyst
}

\author{
Daisuke Miura*, Tomoya Machinami \\ Department of Chemistry, College of Science and Technology, Meisei University, Hino, Tokyo, Japan \\ Email: ${ }^{*}$ daisuke.miura@meisei-u.ac.jp
}

Received 23 October 2014; revised 24 November 2014; accepted 25 December 2014

Copyright (C) 2015 by authors and Scientific Research Publishing Inc.

This work is licensed under the Creative Commons Attribution International License (CC BY). http://creativecommons.org/licenses/by/4.0/

(c) (i) Open Access

\begin{abstract}
Prolinamido-glycoside catalyzed asymmetric aldol reaction in aqueous media is reported. The reactions are rapid and highly stereoselective when water is used as solvent. The stereoselectivities were under influence of configurations of a prolyl residue of the catalyst and $\alpha$-chiral aldehydes. Water soluble prolinamido-glycoside catalysts are easily separable from reaction mixture and can be recycled and re-used several times.
\end{abstract}

\section{Keywords}

Organocatalyst, Aldol Reaction, Carbohydrate, Water-Compatible, Prolinamide

\section{Introduction}

Proline catalyzed stereoselective aldol reaction is convenient method for the preparation of synthetic intermediates of natural products [1]. Although water is regarded as an ideal solvent in terms of its environmental influence and low cost, proline and the analogs have not been shown to act as an asymmetric catalyst in aqueous media [2] [3]. Water is known to inhibit the stereocontrol by interrupting hydrogen bonds of the stabilized transition state. Since proline and the analogs have shown decreased selectivity in water and do not seem to act as an aldolase [4] [5], development of water-compatible organocatalysts has been of interest, especially for prebiotic synthesis of carbohydrates [6]-[10]. In previous study, amino acyl sugar derivatives have demonstrated as water compatible organocatalysts, and prolinamido-glycosides, methyl 2-(L-prolyl)amido- $\alpha$-D-glucopyranoside 1 and methyl 2-(D-prolyl)amido- $\alpha$-D-glucopyranoside 2 , offer useful potential as catalysts for aqueous aldol reaction [11]. In aqueous media, the prolinamido-glycosides exhibited catalyzing the formation of aldol products with

*Corresponding author.

How to cite this paper: Miura, D. and Machinami, T. (2015) Stereoselective Aldol Reaction in Aqueous Solution Using Prolinamido-Glycosides as Water-Compatible Organocatalyst. Modern Research in Catalysis, 4, 20-27.

http://dx.doi.org/10.4236/mrc.2015.41003 
stereocontrol, and the observed stereoselectivity in the aldol reaction was in general accordance with the FelkinAnh model when the $\alpha$-chiral aldehydes were used [12]. Such carbohydrate-based prolinamido-glycoside catalysts are easy to handle and recover, and can offer interesting possibilities for preparing various carbohydrates in the asymmetric aldolreaction. In this report, the prolinamido-glycoside catalyzed asymmetric aqueous aldol reaction has described in detail.

\section{Experimental}

\subsection{General Information}

NMR spectra were recorded on JEOL JNM-A500 and Varian NB 600 spectrometers. All chemical shifts are quoted in ppm and were referenced to TMS and residual solvent as internal standards. HPLC analysis was performed using a Shimazu LC-10AD vp using Chiralpack AS-H and AD-H from Daicel Chemical Industries, Ltd. Mass spectra were recorded on JEOL JMS-T100CS spectrometer. Optical rotations were measured on JASCO Model DIP-1000 polarimeter. Melting points were determined in open glass capillaries in Yazawa apparatus, and are uncorrected. Evaporations were performed under diminished pressure with a rotaryevaporator at $40^{\circ} \mathrm{C}$ or less unless otherwise stated. Thin-layer chromatography (TLC) was performed on pre-coated plates of silica gel (DC-Fertigpettenkiesge 160F 256, Merck). Spots were detected by spraying the plate with $10 \%$ aqueous $\mathrm{H}_{2} \mathrm{SO}_{4}$ or molybdic acid followed by heating. Column chromatography was performed on Wacogel C-200.

\subsection{Catalyst Preparation}

Methyl 2-(L-prolyl)-amido- $\alpha$-D-glucopyranoside and methyl 2-(D-prolyl)-amido- $\alpha$-D-glucopyranoside were obtained from D-glucosamine hydrochloride via methyl 2-amino-2-deoxy- $\alpha$-D-glucopyranoside, followed by condensation with $N$-Boc-proline. Methyl 2-amino-2-deoxy- $\alpha$-D-glucopyranoside was prepared from D-glucosamine hydrochloride by adapting the procedure described by Suami [13] and Jeffs [14]. Methyl 2-amino-2deoxy- $\alpha$-D-glucopyranoside was coupled to $N$-Boc-proline by treatment with EDCI as a coupling reagent in an ice cooling mixture of methanol and dichloromethane. The prolinamido-glycoside catalysts (1 and $\mathbf{2})$ were obtained by hydrogenolysis of the Boc-protecting group followed by neutralization of resulting hydrochlorides with ion-exchange resin. The structure of the prolinamide catalysts is shown in Figure 1.

\subsection{Substrates Preparation}

2,3-O-Isopropylidene-D-glyceraldehyde was prepared from D-mannitol according to the procedure of Schmid [15]. 2,3-O-Isopropylidene-L-glyceraldehyde was prepared from L-erythulose as described by Vandewalle [16]. 2,2-Dimethyl-1,3-dioxan-5-one was prepared from trishydroxyaminomethane hydrochloride as described by Doyle [17].

\subsection{General Procedure for the Aldol Reaction of Prolinamido-Glycosides}

Aldehyde (1.0 equiv) and ketone (10 equiv) were added to a stirred solution of the catalyst (0.05 - 0.3 equiv) in $\mathrm{H}_{2} \mathrm{O}$ as a sole solvent, and the solution was stirred at r.t. After TLC indicated consumption of the starting materials, the solution was extracted with EtOAc, washed with $\mathrm{H}_{2} \mathrm{O}$, dried $\left(\mathrm{Na}_{2} \mathrm{SO}_{4}\right)$, and concentrated to dryness. The residue was purified by column chromatography on silica gel to afford the aldol products. After completion of the reactions, the prolinamido-glycoside catalysts could be separated by an extraction. Concentration of the aqueous layer, followed by recrystallization from 2-PrOH gave ca. $75 \%$ recovery of the catalyst. Use of recovered catalysts for the aldol reactions showed that the second aldol reactions were indistinguishable from the first aldol reactions in terms of yield and stereoselectivity.

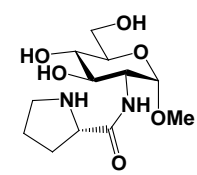

cat.1

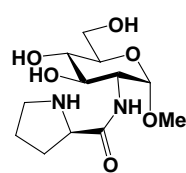

cat.2<smiles>O=C(NCCO)[C@H]1CCCN1</smiles>

cat.3

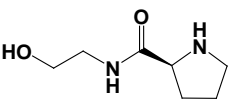

cat.4

Figure 1. Structure of the prolinamide catalysts. 


\section{Results and Discussion}

\subsection{Stereoselectivity of the Prolinamido-Glycosides Catalyzed Aldol Reaction}

Various conditions were evaluated for the selective aldol reaction of acetone with isobutyraldehyde (Scheme 1), and the results are summarized in Table 1 . The best results were obtained when the reaction was performed using 0.1 equivalent of the catalyst. When the amount of catalyst was decreased from 0.1 to 0.05 equivalents, the yield significantly decreased, and the reaction time increased. Further, a change of solvent from water to DMSO markedly decreased setereoselectivity of the reactions. This result shows prolinamido-glycoside act as watercompatible organocatalyst. Formations of the aldol condensation product nor the self aldol product were not observed. As the $(R)$-enantiomer was obtained in $90 \%$ yield with $89 \%$ ee by L-prolinamido-glycoside (1) catalyzed aldol reaction, the attack of acetone was selectively took place at $r e$-face of isobutyraldehyde under L-prolinamido-glycoside catalyzed condition. In contrast, the (S)-enantiomer was formed $89 \%$ yield with $91 \%$ ee under D-prolinamido-glycoside catalyzed condition. Considering the conformation of prochiralisobutyraldehyde by adopting the Felkin-Anh model, the two enantiotopic faces are equivalent, hence the enantioselectivity of the reaction was due solely to the preference of the catalyst. When 2,3-O-isopropylidene-glyceraldehyde was used in the reaction (Scheme 2), matched and mismatched cases were observed (Table 2). Chiral aldehydes possess two diastereotopic faces, and are not equivalent. Because of greater accessibility due to the asymmetric effects, less hindered si-faces of (2R)-aldehydes are more reactive than more crowded re-faces, and re-face of (2S)-aldehydes are more reactive (Figure 2). As expected, the reaction between acetone and (2R)-2,3-O-isopropylidene-D-glyceraldehyde under D-prolinamido-glycoside (1) catalyzed condition gave the 1,3-dideoxy-4,5-di-Oisopropylidene-D-erythro-hexulose with high (94\%) de. In the case of (2S)-2,3-O-isopropylidene-L-glyceraldehyde, L-prolinamido-glycoside (2) catalyzed condition gave high (81\%) de.The method was applied to Dglyceraldehyde in the free form (Scheme 3), and the results are shown in Table 3. Although the relatively low diastereofacial selectivities exhibited by the free sugar-chain may be attributed to the conformational mobility of the chain, the reaction rates were still fast. Reaction of D-glyceraldehyde with acetone in an aqueous solution of D-prolinamide (2) gave the anti-diastereomer, 1,3-dideoxy-D-erythro-hexulose [18]-[20] (94\% yield, 76\% de) was obtained. Similarly, the reaction of D-glyceraldehyde with acetone under the L-prolinamide (1) catalyzed condition afforded the syn-diastereomer, 1,3-dideoxy-D-threo-hexulosein 87\% yield with 67\% de.

Table 1. Influence of solvent and catalyst amount on prolinamide catalyzed aldol reaction of acetone with isobutyraldehyde.

\begin{tabular}{ccccccc}
\hline Entry & Catalyst & Amount of catalyst (equiv) & Solvent & Time (h) & Yield (\%) & ee $^{\mathrm{a}}(\%)$ \\
\hline 1 & $\mathbf{1}$ & 0.3 & $\mathrm{H}_{2} \mathrm{O}$ & 0.5 & 98 & $86(R)$ \\
2 & $\mathbf{1}$ & 0.1 & $\mathrm{H}_{2} \mathrm{O}$ & 0.5 & 90 & $89(R)$ \\
3 & $\mathbf{1}$ & 0.05 & $\mathrm{H}_{2} \mathrm{O}$ & 2 & 82 & $89(R)$ \\
4 & $\mathbf{1}$ & 0.1 & $\mathrm{DMSO}$ & 48 & 11 & $19(R)$ \\
5 & $\mathbf{2}$ & 0.3 & $\mathrm{H}_{2} \mathrm{O}$ & 0.5 & 98 & $89(S)$ \\
6 & $\mathbf{2}$ & 0.1 & $\mathrm{H}_{2} \mathrm{O}$ & 0.5 & 89 & $91(S)$ \\
7 & $\mathbf{2}$ & 0.05 & $\mathrm{H}_{2} \mathrm{O}$ & 2 & 81 & $87(S)$ \\
8 & $\mathbf{2}$ & $\mathrm{DMSO}_{(S)}$ & 48 & 23 & $31(S)$ \\
9 & $\mathbf{3}$ & 0.1 & $\mathrm{H}_{2} \mathrm{O}$ & 24 & 32 & $83(R)$ \\
10 & $\mathbf{3}$ & 0.3 & $\mathrm{H}_{2} \mathrm{O}$ & 24 & 25 & $76(R)$ \\
11 & $\mathbf{3}$ & 0.1 & $\mathrm{H}_{2} \mathrm{O}$ & 48 & 26 & $81(R)$ \\
12 & $\mathbf{3}$ & 0.05 & $\mathrm{DMSO}_{(R)}$ & 48 & 11 & $68(R)$ \\
13 & $\mathbf{4}$ & 0.1 & $\mathrm{H}_{2} \mathrm{O}$ & 24 & 36 & $83(S)$ \\
14 & $\mathbf{4}$ & 0.3 & $\mathrm{H}_{2} \mathrm{O}$ & 24 & 22 & $79(S)$ \\
15 & $\mathbf{4}$ & 0.1 & $\mathrm{H}_{2} \mathrm{O}$ & 48 & 24 & $75(S)$ \\
16 & $\mathbf{4}$ & 0.05 & $\mathrm{DMSO}$ & 48 & 12 & $61(S)$ \\
\hline
\end{tabular}

${ }^{\mathrm{a}}$ Determined by HPLC analysis. 


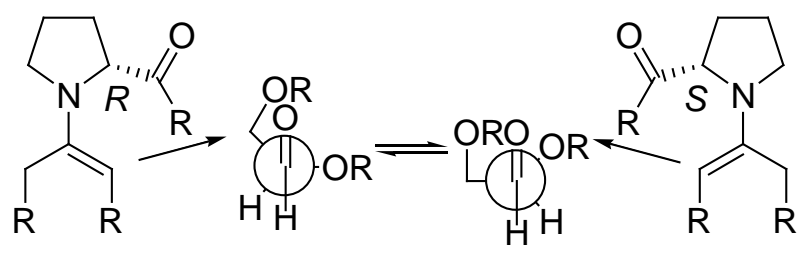

$$
\begin{array}{ll}
\text { si-face attack } & \text { re-face attack } \\
\text { D-prolinamide } & \text { L-prolinamide }
\end{array}
$$

Figure 2. Diastereofacial selectivity on $\alpha$-chiral aldehydes.<smiles>CC(=O)CC(O)C(C)C</smiles>

acetone

isobutyraldehyde

Scheme 1. Prolinamide-catalyzed aldol reaction of acetone with isobutyraldehyde.<smiles>CC(=O)CC(O)C(C)COC(C)=O</smiles>

2,3-O-isopropylidene-glyceraldehyde

Scheme 2. Prolinamide-catalyzed aldol reaction of acetone with 2,3-O-isopropylidene-D-glyceraldehyde.<smiles>CC(=O)CC(O)[C@@H](O)CO</smiles>

acetone D-glyceraldehyde

Scheme 3. Prolinamide-catalyzed aldol reaction of acetone with D-glyceraldehyde in the free form.

Table 2. Prolinamide-catalyzed aldol reaction of acetone with 2,3-O-isopropylidene-D-glyceraldehyde.

\begin{tabular}{cccccc}
\hline Entry & Catalyst & Configuration of substrate & Time (h) & Yield (\%) & de $^{\text {a }}(\%)$ \\
\hline 1 & $\mathbf{1}$ & $(2 R)$ & 1 & 91 & 24 (syn) \\
2 & 2 & $(2 R)$ & 1 & 88 & 94 (anti) \\
3 & $\mathbf{3}$ & $(2 R)$ & 48 & 61 & 71 (syn) \\
4 & $\mathbf{4}$ & $(2 R)$ & 48 & 52 & 79 (anti) \\
5 & $\mathbf{1}$ & $(2 S)$ & 1 & 96 & 81 (anti) \\
6 & $\mathbf{2}$ & $(2 S)$ & 1 & 75 & 63 (anti) \\
\hline
\end{tabular}

${ }^{\mathrm{a}}$ Determined by ${ }^{1} \mathrm{H}$ NMR analysis. 
In a parallel series of experiments, known [21] [22] prolinamido-ethanols (3 and 4) were also used as catalyst in the aqueous aldol reaction of isobutyraldehyde and D-glyceraldehyde. Although the catalysts possess minimum structural requirements for prolinamido-glycoside catalysts and acted as water-compatible organocatalyst, the yields and stereoselectivities were reduced when compared with prolinamido-glycoside (1 and $\mathbf{2})$ catalyzed conditions. The results suggested that the efficiency of the chiral carbohydrate auxiliaries which control stereochemistry of enamine mechanism in the aqueous aldol reaction [11].

\subsection{Synthesis of Carbohydrates by the Prolinamido-Glycosides Catalyzed Aldol Reaction}

As shown in Scheme 4, the prolinamide catalyzed aldol reaction was applied to carbohydrate synthesis. Each of isopropylidene protected D-psicose and D-tagatose was obtained by treating 2,2-dimethyl-1,3-dioxan-5-one with 2,3-O-isopropylidene-D-glyceraldehyde in the presence of the prolinamido-glycoside in water at room temperature. L-Prolinamido-glycoside (1) catalyzed condition gave protected D-tagatose in $72 \%$ yield with $76 \%$ de, and D-prolinamido-glycoside (2) catalyzed condition gave protected D-psicose in $69 \%$ yield with $91 \%$ de, respectively. The isopropylidene protected D-psicose and D-tagatosehad properties concordant with those already reported [23]-[26]. The product ratio of psico and tagato was determined by ${ }^{1} \mathrm{H}$ NMR integration of the singlet methyl peaks of the isopropylidene groups in the product mixture, and signals attributable to the syn-diastereomers, isopropylidene-D-fructose and isopropylidene-D-sorbose, were not observed in the products. When the dihydroxyacetone dimer and glycolaldehyde dimer were treated under the prolinamido-glycoside catalyzed

Table 3. Prolinamide-catalyzed aldol reaction of acetone with D-glyceraldehyde in the free form.

\begin{tabular}{ccccc}
\hline Entry & Catalyst & Time (h) & Yield (h) & $\operatorname{de}^{\mathrm{a}}(\%)$ \\
\hline 1 & $\mathbf{1}$ & 1 & 87 & 67 (syn) \\
2 & $\mathbf{2}$ & 1 & 94 & 76 (anti) \\
3 & $\mathbf{3}$ & 24 & 21 & 38 (syn) \\
4 & $\mathbf{4}$ & 24 & 27 & 49 (anti) \\
\hline
\end{tabular}

${ }^{\mathrm{a}}$ Determined by ${ }^{1} \mathrm{H}$ NMR analysis.<smiles>CC1(C)OCC(=O)CO1</smiles><smiles>CC1(C)OC[C@H](C=O)O1</smiles><smiles>CO</smiles><smiles>CC1(C)OC[C@@H]([C@H](O)[C@H]2OC(C)(C)OCC2=O)O1</smiles>

D-tagatose<smiles>CC1(C)OC[C@H]([C@@H](O)[C@H]2OC(C)(C)OCC2=O)O1</smiles>

2,2-dimethyl-1,3-dioxan-5-one<smiles>O=C(CO)CO</smiles>

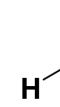<smiles>O=C1CCCC1</smiles><smiles>O</smiles>

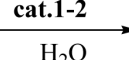
dihydroxyacetone glycolaldehyde<smiles>C=CC=C</smiles><smiles>[C]1C=CC=C1</smiles><smiles>OCC1(O)COC(O)(CO)CO1</smiles><smiles>OC1COC(O)CO1</smiles>

Scheme 4. Synthesis of carbohydrates by prolinamide catalyzed aldol reaction. 
conditions in aqueous media, each of D-xylulose [27]-[30] and D-ribulose [31]-[34] was selectively obtained from L-prolinamide and D-prolinamide conditions, respectively, but in low to moderate yields. L-Prolinami-doglycoside (1) catalyzed condition gave D-xylulose in 39\% yield with 77\% de, and D-prolinamido-glycoside (2) catalyzed condition gave D-riburose in $38 \%$ yield with $81 \%$ de. The ${ }^{1} \mathrm{H}$ NMR spectra of which were identical with the authentic samples of D-xylulose and D-ribulose, and the ratios of the two epimers were determined by comparison of the $\mathrm{H}-1$ signals in the ${ }^{1} \mathrm{H}$ NMR spectra of the initial mixtures.

\section{Conclusion}

Prolinamido-glycosides catalyzed stereoselective aldol reaction of acetone in aqueous media, and ketoses were stereoselectively synthesized. The diastereofacial selectivities in the aldol reaction were mainly controlled by the stereochemistry at the prolyl residue of the catalysts and the conformational disposition of $\alpha$-chiral aldehydes, and were in general accordance with the Felkin-Anh model. The catalysts showed substrate selectivity for water soluble aldehyde, and well controlled stereochemical generation. Prolinamido-glycosides were also capable of catalyzing the aldol reaction of aldoses in unprotedted form and hence the prolinamido-glycosides catalyzed aldol reaction has potential for understanding prebiotic routes of carbohydrates.

\section{References}

[1] Tanaka, F. and Barbas, C.F. (2007) Enantioselective Organocatalysis, Reactions and Experimental Procedures. In: Dalko, P.I., Ed., Weiley-VCH, Weinheim, 19-55.

[2] List, B., Lerner, R.A. and Barbas III, C.F. (2000) Proline-Catalyzed Direct Asymmetric Aldol Reactions. Journal of the American Chemical Society, 122, 2395-2396. http://pubs.acs.org/doi/abs/10.1021/ja994280y http://dx.doi.org/10.1021/ja994280y

[3] Sakthivel, K., Not, W., Bui, T. and Barbas III, C.F. (2001) Amino Acid Catalyzed Direct Asymmetric Aldol Reactions: A Bioorganic Approach to Catalytic Asymmetric Carbon-Carbon Bond-Forming Reactions. Journal of the American Chemical Society, 123, 5260-5267. http://pubs.acs.org/doi/abs/10.1021/ja010037z

[4] Dickerson, T.J. and Janda, K.D. (2002), Aqueous Aldol Catalysis by a Nicotine Metabolite. Journal of the American Chemical Society, 124, 3220-3221. http://pubs.acs.org/doi/pdf/10.1021/ja017774f http://dx.doi.org/10.1021/ja017774f

[5] Dickerson, T.J., Lovell, T., Meijler, M.M., Noodleman, L. and Janda, K.D. (2004)Nornicotine Aqueous Aldol Reactions: Synthetic and Theoretical Investigations into the Origins of Catalysis. The Journal of Organic Chemistry, 69, 6603-6609. http://pubs.acs.org/doi/abs/10.1021/jo048894j http://dx.doi.org/10.1021/jo048894j

[6] Pedatella, S., De Nisco, M., Mastroianni, D., Naviglio, D., Nucci, A. and Caputo, R. (2011) Diastereo- and Enantioselective Direct Aldol Reactions in Aqueous Medium: A New Highly Efficient Proline-Sugar Chimeric Catalys, Advanced Synthesis \& Catalysis, 353, 1443-1446. http://onlinelibrary.wiley.com/doi/10.1002/adsc.201100143/abstract http://dx.doi.org/10.1002/adsc.201100143

[7] Burroughs, L., Vale, M.E., Gilks, J.A., Forintos, H., Hayes, C.J. and Clarke, P.A. (2010) Efficient Asymmetric Organocatalytic Formation of Erythrose and Threose under Aqueous Conditions. Chemical Communications, 46, 4776-4778. http://pubs.rsc.org/en/content/articlelanding/2010/cc/c0cc00613k\#!divAbstract http://dx.doi.org/10.1039/c0cc00613k

[8] Maya, V., Raj, M. and Singh, V.K. (2007) Highly Enantioselective Organocatalytic Direct Aldol Reaction in an Aqueous Medium. Organic Letters, 9, 2593-2595. http://dx.doi.org/10.1021/ol0710131

[9] Ramasastry, S.S.V., Albertshofer, K., Utsumi, N. and Barbas III, C.F. (2008) Water-Compatible Organocatalysts for Direct Asymmetric syn-Aldol Reactions of Dihydroxyacetone and Aldehydes. Organic Letters, 10, 1621-1624. http://pubs.acs.org/doi/abs/10.1021/ol8002833

[10] Kofoed, J., Reymond, J.-L. and Darbre, T. (2005) Prebiotic Carbohydrate Synthesis: Zinc-Proline Catalyzes Direct Aqueous Aldol Reactions of $\alpha$-Hydroxy Aldehydes and Ketones. Organic \& Biomolecular Chemistry, 3, 1850-1855. http://pubs.rsc.org/en/content/articlelanding/2005/ob/b501512j\#!divAbstract

[11] Tsutsui, A., Takeda, H., Kimura, M., Fujimoto, T. and Machinami, T. (2007) Novel Enantiocontrol System with Aminoacyl Derivatives of Glucoside as Enamine-Based Organocatalysts for Aldol Reaction in Aqueous Media. Tetrahedron Letters, 48, 5213-5217. http://www.sciencedirect.com/science/article/pii/S0040403907010350

[12] Miura, D., Fujimoto, T., Tsutsui, A. and Machinami, T. (2013) Stereoselective Synthesis of Ketoses by Aldol Reaction Using Water-Compatible Prolinamide Catalysts in Aqueous Media. Synlett, 24, 1501-1504. https://www.thieme-connect.com/products/ejournals/abstract/10.1055/s-0033-1339197 
[13] Suami, T. (1982) Nitrosourea derivatives, Fr, Demande, Fr 2493318, A1, 19820507.

[14] Jeffs, P.W., Chan, G., Sitrin, R., Holder, N., Roberts, G.D. and DeBrosse, C. (1985) The Structure of Glycolipid Components of the Aridicin Antibiotic Complex. The Journal of Organic Chemistry, 50, 1726-1731. http://pubs.acs.org/doi/abs/10.1021/jo00210a030 http://dx.doi.org/10.1021/jo00210a030

[15] Schimd, C.R., Bryant, J.D., Dowlatzedah, M., Phillips, J.L., Prather, D.E., Schantz, R.D., Sear, N.L. and Vianco, C.S. (1991) Synthesis of 2,3-O-isopropylidene-D-glyceraldehyde in High Chemical and Optical Purity: Observations on the Development of a Practical Bulk Process. The Journal of Organic Chemistry, 56, 4056-4058. http://pubs.acs.org/doi/abs/10.1021/jo00012a049 http://dx.doi.org/10.1021/jo00012a049

[16] Wilde, H.D., Clercq, P.D. and Vandewalle, M. (1987) L-(S)-erythrulose a Novel Precursor to L-2,3-O-isopropylideneC3 Chirons. Tetrahedron Letters, 28, 4757-4758. http://dx.doi.org/10.1016/S0040-4039(00)96618-8 http://www.sciencedirect.com/science/article/pii/S0040403900966188

[17] Forbes, D.C., Ene, D.G. and Doyle, M.P. (1998) Stereoselective Synthesis of Substituted 5-Hydroxy-1,3-dioxanes. Synthesis, 6, 879-882. https://www.thieme-connect.com/products/ejournals/abstract/10.1055/s-1998-2090 http://dx.doi.org/10.1055/s-1998-2090

[18] West, B.F., Bhat, K.V. and Zorbach, W.W. (1968) 2-Deoxy Sugars Part XIII. 1,3-Dideoxy-d-erythro-hexulose. Carbohydrate Research, 8, 253-261. http://www.sciencedirect.com/science/article/pii/S0008621500822302 http://dx.doi.org/10.1016/S0008-6215(00)82230-2

[19] Kito, Y., Kawakishi, S. and Namiki, M. (1980) A Novel Reaction of Sugars with Anion Radical of Carbon Dioxide Produced from Formate. Agricultural and Biological Chemistry, 44, 2695-2701. https://www.jstage.jst.go.jp/article/bbb1961/44/11/44_11_2695/_article http://dx.doi.org/10.1271/bbb1961.44.2695

[20] Torsell, K.B.G., Hazell, A.C. and Hazell, R.G. (1985) Silylnitronates and NITRILE Oxides in Organic Synthesis. A Novel Route to D,L-deoxysugars. Use of Aluminum Oxide as Solid Phase Base for generation of. Tetrahedron, 41, 5569-5575. http://www.sciencedirect.com/science/article/pii/S0040402001913584

[21] Iwamoto, H., Yoshida, M., Yamamoto, M. and Tanuma, T. (1984) European Patent Applications, EP 123444A1 19841031.

[22] Tamura, T., Iwamoto, H., Yoshida, M. and Yamamoto, M. (1985) Japanese Kokai Tokkyo Koho, JP60172996 A19850906.

[23] Majewski, M. and Nowak, P.J. (2000) Aldol Addition of Lithium and Boron Enolates of 1,3-Dioxan-5-ones to Aldehydes. A New Entry into Monosaccharide Derivatives. The Journal of Organic Chemistry, 65, 5152-5160. http://pubs.acs.org/doi/abs/10.1021/jo0002238 http://dx.doi.org/10.1021/jo0002238

[24] Majewski, M. and Nowak, P. (1999) Stereoselective Synthesis of Protected Ketohexoses via Aldol Reaction of Chiral Dioxanone Enolate. Synlett, 9, 1447-1449. http://dx.doi.org/10.1055/s-1999-2862 https://www.thieme-connect.com/products/ejournals/abstract/10.1055/s-1999-2862

[25] Grondal, C. and Enders, D. (2006) Direct Asymmetric Organocatalytic de Novo Synthesis of Carbohydrates. Tetrahedron, 62, 329-337. http://www.sciencedirect.com/science/article/pii/S0040402005016522 http://dx.doi.org/10.1016/j.tet.2005.09.060

[26] Suri, J.T., Mitsumori, S., Albertshofer, K., Tanaka, F. and Barbas III, C.F. (2006) Dihydroxyacetone Variants in the Organocatalytic Construction of Carbohydrates: Mimicking Tagatose and Fuculose Aldolases. The Journal of Organic Chemistry, 71, 3822-3828. http://pubs.acs.org/doi/abs/10.1021/jo0602017 http://dx.doi.org/10.1021/jo0602017

[27] Hann, R.M., Tilden, E.B. and Hudson, C.S.J. (1938) The Oxidation of Sugar Alcohols by Acetobacter suboxydans. Journal of the American Chemical Society, 60, 1201-1203. http://pubs.acs.org/doi/abs/10.1021/ja01272a058 http://dx.doi.org/10.1021/ja01272a058

[28] Hochster, R.M. and Watson, R.W. (1953) XYLOSE ISOMERASE. Journal of the American Chemical Society, 75, 3284-3285. http://pubs.acs.org/doi/abs/10.1021/ja01109a516 http://dx.doi.org/10.1021/ja01109a516

[29] Bean, R.C. and Hassid, W.Z.J. (1955) Synthesis of Disaccharides with Pea Preparations. Journal of the American Chemical Society, 77, 5737-5738. http://pubs.acs.org/doi/abs/10.1021/ja01626a081 http://dx.doi.org/10.1021/ja01626a081

[30] Hollmann, S. and Touster, O. (1956) An Enzymatic Pathway from L-Xylulose to D-Xylulose. Journal of the American Chemical Society, 78, 3544-3545. http://pubs.acs.org/doi/abs/10.1021/ja01595a080 
http://dx.doi.org/10.1021/ja01595a080

[31] Suzuki, K., Yuki, Y. and Mukaiyama, T. (1981) The Stereoselective Synthesis of D-Ribulose. Chemistry Letters, 11, 1529-1532. https://www.jstage.jst.go.jp/article/cl1972/10/11/10_11_1529/_article http://dx.doi.org/10.1246/cl.1981.1529

[32] Drueckhammer, D.G., Durrwachter, J.R., Pederson, R.L., Richard, L., Crans, D.C., Daniels, L. and Wong, C.H. (1989) Reversible and in Situ Formation of Organic Arsenates and Vanadates as Organic Phosphate Mimics in Enzymatic Reactions: Mechanistic Investigation of Aldol Reactions and Synthetic Applications. The Journal of Organic Chemistry, 54, 70-77. http://pubs.acs.org/doi/abs/10.1021/j000262a021

[33] Vuorien, T. and Serianni, A.S. (1991) Synthesis of D-erythro-2-pentulose and D-threo-2-pentulose and Analysis of the 13C- and 1H-n.m.r. Spectra of the 1-13C- and 2-13C-Substituted Sugars. Carbohydrate Research, 209, 13-31.

http://www.sciencedirect.com/science/article/pii/000862159180142A http://dx.doi.org/10.1016/0008-6215(91)80142-A

[34] Fisher, M., Kaehling, H. and Schmid, W. (2011) Gram Scale Synthesis of 3-Fluoro-1-hydroxyacetone Phosphate: A Novel Donor Substrate in Rabbit Muscle Aldolase-Catalyzed Aldol Reactions. Chemical Communications, 47, 66476649. http://pubs.rsc.org/en/content/articlelanding/2011/cc/c1cc11579k\#!divAbstract http://dx.doi.org/10.1039/c1cc11579k 
Scientific Research Publishing (SCIRP) is one of the largest Open Access journal publishers. It is currently publishing more than 200 open access, online, peer-reviewed journals covering a wide range of academic disciplines. SCIRP serves the worldwide academic communities and contributes to the progress and application of science with its publication.

Other selected journals from SCIRP are listed as below. Submit your manuscript to us via either submit@scirp.org or Online Submission Portal.
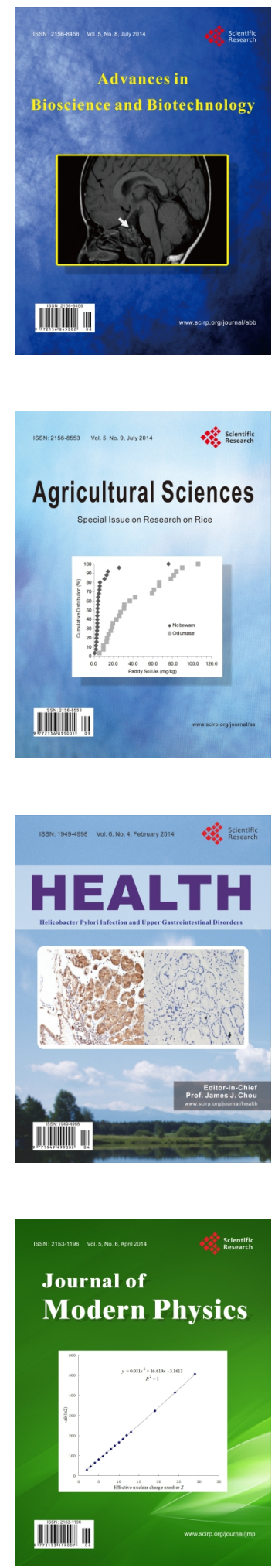
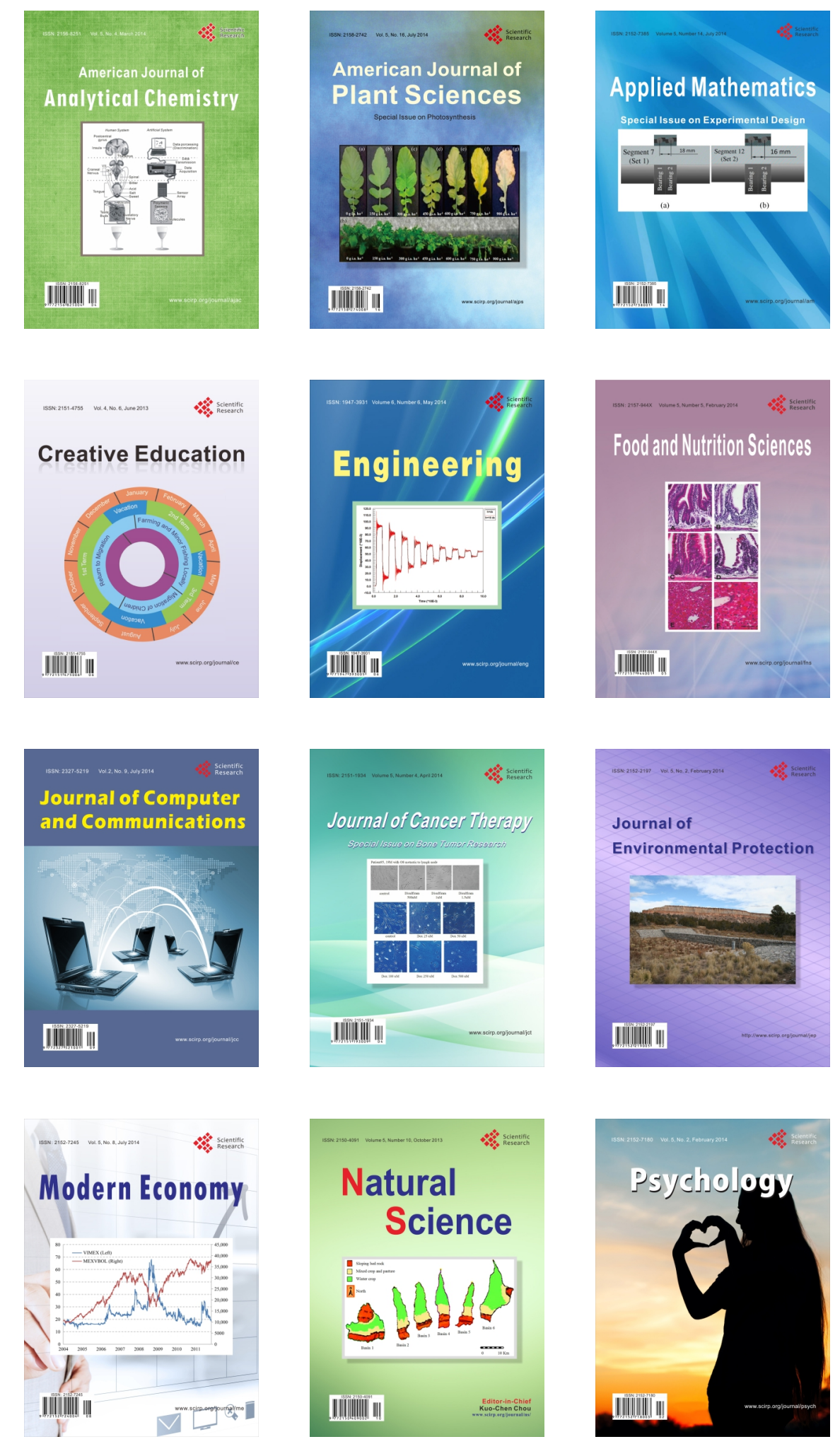